\title{
9
}

Miguel Fernández Díez*

\section{PASOS HACIA UN MARCO EUROPEO DE REGULACIÓN LABORAL}

En los últimos dos años se ha intensificado la actividad reguladora de la UE en materia laboral. Se han aprobado iniciativas con incidencia importante en varios ámbitos del funcionamiento de las empresas, especialmente en aquellas que prestan servicios en otros países de la UE, desplazando para ello a trabajadores, un modo de prestación cada vez más frecuente. Con estas nuevas normas el marco regulatorio comunitario en el ámbito laboral sigue cobrando importancia, una tendencia que previsiblemente continuará en el futuro próximo, caminando hacia la configuración de un marco europeo de regulación laboral. Todo ello aconseja profundizar en estas novedades normativas.

Palabras clave: regulación laboral, desplazamiento de trabajadores, modos de trabajo flexibles, Unión Europea.

Clasificación JEL: J61, K31.

\section{Introducción}

Es un tópico afirmar que la importancia de la normativa europea tiende a pasar desapercibida, pero la intensidad con la que las iniciativas europeas inciden en el entorno regulatorio y de actuación de las empresas sigue haciendo necesario recordar hasta qué punto puede afectar a su funcionamiento y debe ser tenido en cuenta. El ámbito laboral no es una excepción, y recientemente, en especial durante los

\footnotetext{
* Técnico Comercial y Economista del Estado. Consejero de Trabajo, Migraciones y Seguridad Social en la Representación Permanente de España ante la UE, Bruselas.

Agradezco la ayuda de Juan Antonio Elena en la elaboración de este artículo.

Versión de octubre de 2019.

DOI: https:/doi.org/10.32796/bice.2019.3117.6932
}

últimos meses, se han adoptado varias iniciativas que constituyen pasos decididos hacia la configuración de un marco europeo de regulación laboral con gran importancia para la vida diaria de las empresas.

En julio de 2018 se publicó una nueva normativa que afecta a las empresas que desplazan trabajadores para prestar servicios en otros países de la UE. Se trata de una revisión de las condiciones en las que puede producirse el desplazamiento de trabajadores, que es en muchas ocasiones un elemento esencial de la libre prestación de servicios.

En julio de 2019 se han publicado otras tres normas que afectan en distinta medida a las empresas: una directiva con normas mínimas sobre condiciones de trabajo, que pretende luchar contras las formas extremas de $\square$ 
precariedad; otra directiva que establece la obligación de implantar a nivel nacional permisos familiares y condiciones flexibles de trabajo para facilitar la conciliación de la vida personal y laboral; y, finalmente, un reglamento comunitario que crea una Autoridad Laboral Europea. La autoridad está llamada a ser el referente en materia de control y persecución de los abusos laborales en la UE, de forma análoga al cometido que la Inspección de Trabajo desarrolla en España.

Finalmente, en estos meses, la UE ha continuado actualizando la normativa sobre sustancias cancerígenas, con reglas que en determinados sectores pueden tener un impacto notable. Asimismo, se ha finalizado la tramitación de dos normas horizontales con incidencia en el funcionamiento de las empresas: una directiva que somete a control los procesos de reestructuración empresarial para proteger los derechos de los trabajadores y otra que obliga a garantizar canales de denuncia interna y protección para los trabajadores que denuncien malas prácticas de las empresas.
Estos pasos evidencian la relevancia que está adquiriendo el nivel europeo de toma de decisiones en materia laboral y de cómo el seguimiento de los avances en la normativa comunitaria es esencial para tener una visión actualizada del marco de actuación de las empresas en el entorno europeo.

Con este objetivo, este artículo presenta las principales implicaciones para las empresas de estas nuevas normas. En el último apartado se apuntan posibles iniciativas de ámbito europeo que pueden continuar el desarrollo de ese marco de regulación laboral en un futuro próximo.

\section{Nuevas normas sobre desplazamiento de trabajadores}

De las iniciativas aprobadas recientemente en materia laboral en el ámbito europeo, la medida que puede tener más repercusión en la actividad de las empresas es la revisión de la directiva sobre desplazamiento de trabajadores: Directiva (UE) 2018/957.

\section{RECUADRO 1 \\ EL DESPLAZAMIENTO DE TRABAJADORES COMO COMPLEMENTO NECESARIO DE LA LIBRE PRESTACIÓN DE SERVICIOS EN EL MERCADO ÚNICO}

Desde finales de 1996 la UE cuenta con una norma reguladora del desplazamiento de trabajadores (más conocido por el término inglés de posting) asociado a la prestación de un servicio en un país de destino por una empresa establecida en un país distinto (país de origen) (Directiva 96/71/CE).

El régimen de posting de trabajadores busca un equilibrio entre facilitar la libre prestación de servicios y garantizar a los trabajadores desplazados un mínimo de derechos. Por ello, asegura a estos que se respetarán las normas del país de destino en cuanto a seguridad y salud en el trabajo, protección de mujeres embarazadas, protección contra la discriminación, jornadas máximas de trabajo, duración mínima de vacaciones y, especialmente importante, el salario mínimo aplicable en el lugar de desplazamiento. Es una excepción a la regla general de que deben aplicarse todas las normas laborales y de seguridad social del país donde se trabaja.

El régimen de desplazamiento ha facilitado una mayor competencia entre empresas prestadoras de servicios de la UE incluso antes de la entrada en vigor de la más conocida directiva de servicios (Directiva 2006/123/CE).

Sin embargo, no ha estado libre de polémica. La normativa de 1996 era muy sencilla y flexible, y con escasos instrumentos de control. Con el tiempo y la intensificación de este modo de prestación de servicios se acumularon algunos problemas, con varios casos relevantes ante el Tribunal de Justicia de la UE.

La incomodidad de varios países miembros ante lo que consideraban abusos del régimen de desplazamiento ya dio lugar a una nueva norma en 2014 (con plazo de trasposición hasta junio de 2016) que, sin cambiar el régimen, pretendía mejorar los instrumentos prácticos de lucha contra el fraude y los abusos.

La llamada directiva de aplicación (Directiva 2014/67/UE) presta especial atención a evitar la actividad de las llamadas «empresas buzón». Estas empresas son el paradigma de las actuaciones fraudulentas en el ámbito del posting, puesto que se aprovechan de la normativa de desplazamiento para operar en países de altos salarios sin tener realmente actividad en el país en el que alegan tener su base. 
La nueva directiva de 2018, una revisión parcial de la de 1996, forma parte de un conjunto más amplio de iniciativas dirigidas a alcanzar un mejor equilibrio entre libre prestación y protección. De esa forma se busca restaurar la confianza en la libre movilidad laboral en el mercado único de la UE. La directiva en particular pretende reforzar la igualdad de trato de los trabajadores desplazados con los del lugar donde van a realizar su actividad durante el desplazamiento. Se desarrolla para ello el principio de «igual retribución por igual trabajo en el mismo lugar».

Las medidas concretas de la nueva directiva que deben tener en cuenta las empresas son fundamentalmente:

- Se establece el principio de igualdad de retribución de los trabajadores desplazados con los del lugar donde ejecutan su actividad. Una empresa que desplaza no puede ya conformarse con comprobar que la retribución del trabajador superará la del salario mínimo del país de desplazamiento, sino que debe informarse sobre la retribución bruta total que le correspondería a un trabajador de ese otro país por ese trabajo.

Este principio tiene importantes implicaciones prácticas, ya que obliga a la directiva a delimitar la retribución que debe tomarse como referencia, lo que no es nada sencillo.

En primer lugar, la retribución puede estar (y de hecho suele estarlo en muchos países europeos) determinada por convenios colectivos. En España, identificar el convenio colectivo no siempre es fácil y da lugar a numerosas consultas e incluso conflictos. Hacerlo para las empresas que desplazan trabajadores a otro país de la UE puede ser todavía más complicado.

Por otro lado, la directiva regula qué parte de las retribuciones complementarias deben tenerse en cuenta para dar por cumplida la obligación de igualdad retributiva. A este respecto, la nueva directiva considera incluidos en la remuneración que debe igualarse todos los complementos aplicables, incluidos los de desplazamiento, salvo los que tengan por objeto el reembolso de gastos previamente realizados por el trabajador. Eso sí, en caso de que los complementos que corresponden a reembolso de gastos no estén claramente identificados, se presume que sí son en compensación de gastos.

Todo ello lleva a que la nueva normativa establezca la obligación de los Estados miembros de hacer públicas en una página web única la información necesaria para poder cumplir las nuevas condiciones del posting. En particular, las condiciones y términos de trabajo y los elementos que constituyen la remuneración. La necesidad de transparencia para poder hacer efectiva la nueva obligación llega al extremo de que la directiva prevea que, en caso de que no se haya publicado la información, esta ausencia se tenga en cuenta al imponer las posibles sanciones a las empresas incumplidoras. Cómo operará en la práctica esta previsión es una de las cuestiones complejas que deberá abordarse en los procesos de trasposición.

- Entre las condiciones que deben igualarse se incluyen también las relativas al alojamiento de trabajadores cuando sea el empresario el que lo proporcione a $\triangleright$ 
los trabajadores fuera de su lugar de trabajo habitual.

- Se reduce de 24 a 12 meses el plazo en el que las condiciones específicas de posting aplican a un desplazamiento'. No obstante, en una nueva muestra de equilibrios resultantes de la negociación, la directiva obliga a conceder una prórroga de seis meses en caso de que la empresa lo solicite mediante una notificación motivada. Por otro lado, hay otra novedad que contribuye a endurecer las condiciones de uso de la excepción que supone aplicar las normas del posting (frente a la regla general de aplicación de las normas de seguridad social del país donde se trabaja). Se trata de que el plazo computa también para posibles sustituciones o rotaciones entre trabajadores. Es decir, el plazo máximo no se aplica a un trabajador concreto, sino al desplazamiento que realiza una determinada empresa para una determinada función (por ejemplo, la de jefe de equipo de mantenimiento), aunque lo desarrollen varios trabajadores sucesivamente.

- Se refuerza la aplicación de las condiciones de posting a los desplazamientos de trabajadores contratados por empresas de trabajo temporal (ETT). Esta aplicación se produce ya sea cuando el desplazamiento se realiza por la propia ETT como cuando lo realiza la empresa cliente. Estas eran situaciones hasta ahora no cubiertas por la normativa comunitaria.

Con el final del periodo de trasposición de la directiva, el 30 de julio de 2020, se pasará, algo

1 La directiva original no especifica un plazo, por lo que se aplica el de 24 meses previsto en la normativa de coordinación de seguridad social. más de veinte años después del original, a un nuevo régimen de desplazamiento de trabajadores, que reforzará las garantías de igualdad de trato, especialmente en lo salarial. Sin embargo, también cabe señalar que la nueva normativa conllevará una mayor complejidad administrativa para las empresas, para asegurar el cumplimiento de la nueva normativa.

Para finalizar el análisis de las implicaciones de las novedades sobre posting deben hacerse dos apuntes más. Por un lado, en una de las decisiones más conflictivas de su tramitación, la nueva directiva no es de aplicación al sector de transporte por carretera, que se sujetará a su normativa específica. Por su alta movilidad intrínseca, los conductores se consideraron inicialmente exentos de la aplicación en la directiva de 1996. Sin embargo, la directiva de garantías de aplicación de 2014 sí los mencionaba para dictar sobre esta actividad reglas especiales. La nueva directiva de posting viene a confirmar por parte del legislador que la directiva original sí se les aplica completamente, pero a la vez suspende la aplicación de la nueva hasta que se encuentre una solución específica para el transporte, que será entonces la que se aplique.

Esa solución se está negociando actualmente como parte de la iniciativa «Europa en movimiento», más conocida como «Paquete de movilidad», un conjunto de propuestas sobre el transporte que la Comisión presentó en mayo de $2017^{2}$. Será en ellas donde se concrete de qué forma se aplican las condiciones de posting a los conductores.

Por último, la nueva directiva de posting de 2019 apunta a la conveniencia de reforzar la $\square$

\footnotetext{
2 Una información general sobre la propuesta de la Comisión «Europa en movimiento" puede verse en https://ec.europa.eu/transport/modes/ road/news/2017-05-31-europe-on-the-move_en, teniendo en cuenta que la propuesta está todavía en negociación y puede experimentar cambios.
} 
coordinación entre las autoridades nacionales en materia de lucha contra el fraude. Es más, introduce la obligación de las autoridades nacionales de recabar la información que les requieran sus homólogas de otros países y de contestar a sus consultas en un plazo razonable. Si no lo hacen, se podrá informar a la Comisión para que actúe.

Sin embargo, hasta este momento, la capacidad de la Comisión de forzar una colaboración ha sido limitada, por falta de capacidad ejecutiva en esta materia.

Ese es precisamente el objetivo de la puesta en marcha de la Autoridad Laboral Europea (ALE), aunque está llamada a ser un referente en el control de la normativa laboral más allá de las cuestiones relacionadas directamente con el desplazamiento de trabajadores.

La ALE fue propuesta inicialmente por el Presidente de la Comisión, Jean-Claude Juncker, en su discurso sobre el Estado de la Unión de septiembre de 2017, y ha conseguido completar los trámites para su puesta en marcha en un tiempo récord (Reglamento (UE) 2019/1149). Ya se ha determinado su sede (Bratislava, capital de Eslovaquia) y en octubre de 2019 se ha constituido su Consejo de
Administración, poco más de dos años después de que se propusiera su creación.

En su discurso, Juncker trazaba el símil con la Autoridad Bancaria Europea y consideraba que era absurdo no contar con una autoridad laboral común que velara por la justicia en el mercado interior.

La ALE se concibe, por tanto, como un referente del marco europeo de movilidad laboral y de relaciones laborales cuando esa movilidad está creciendo de manera significativa. Aunque las cifras presentan dificultades ${ }^{3}$ y se recogen con retrasos, las más aproximadas apuntan a un aumento del $58 \%$ de los desplazamientos entre 2011 y 2016 (últimos datos disponibles) (De Wispelaere y Pacolet, 2017).

Con no pocas resistencias, la ALE se ha configurado como un instrumento que podrá tener un papel activo en la vida de las empresas que desplazan trabajadores o que de cualquier otra forma están involucradas en ese $\triangleright$

3 Véase el «Informe sobre la aplicación y ejecución de la Directiva 2014/67/UE del Parlamento Europeo y del Consejo, de 15 de mayo de 2014, relativa a la garantía de cumplimiento de la Directiva 96/71/CE, sobre el desplazamiento de trabajadores efectuado en el marco de una prestación de servicios, y por la que se modifica el Reglamento (UE) n.ำ 1024/2012 relativo a la cooperación administrativa a través del Sistema de Información del Mercado Interior (Reglamento IMI)».

\section{RECUADRO 2}

REVISIÓN DE LOS REGLAMENTOS DE COORDINACIÓN DE LA SEGURIDAD SOCIAL. ¿LA ÚLTIMA PIEZA DEL PUZLE DEL POSTING?

Una pieza más del puzle, la última por el momento, todavía en fase de negociación, aunque muy cerca ya de completarla, es la renovación de los reglamentos comunitarios de coordinación de los sistemas de seguridad social*.

Se trata de normas que tienen un efecto directo y apreciable en algunos aspectos de la actividad empresarial. La propuesta revisa (de nuevo) las condiciones de desplazamiento de los trabajadores, tratando de completar el círculo con la revisión de la directiva de posting.

En particular, establece un límite explícito de 24 meses a partir del cual aplicarán en todo caso las normas de seguridad social del país donde se desarrolle la actividad laboral y se prevé cómo aplicar esas normas en casos de rotaciones.

Por otro lado, se introducen en la normativa algunas restricciones al uso del desplazamiento (algunas de las cuales ya venían aplicándose de facto). Los trabajadores desplazados deberán haber cotizado al menos tres meses en el sistema del país desde el que se desplazan y deberán esperar dos meses entre un desplazamiento y otro al mismo país de destino. Las últimas cuestiones que se están negociando se refieren a las obligaciones documentales del desplazamiento (que están siendo una de las barreras principales al posting en la práctica), la definición de una excepción para los viajes de negocio, precisamente para evitar esas cargas administrativas, y cómo tratar los casos de trabajadores que se desplazan con mucha frecuencia a distintos países.

* Propuesta de Reglamento de Parlamento Europeo y del Consejo por el que se modifican el Reglamento (CE) n. 883/2004, sobre la coordinación de

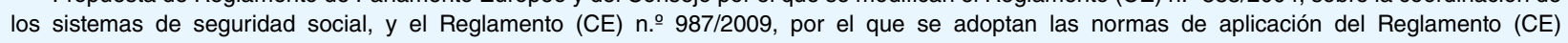
ก. $.983 / 2004$. 
desplazamiento (por ejemplo, contratando servicios que se prestan por trabajadores desplazados).

La ALE será fundamentalmente un instrumento de cooperación entre las autoridades nacionales, cuyas competencias no se ven menoscabadas ni sustituidas por el nuevo organismo. Sus tareas serán:

- Facilitar a las empresas el acceso a la información que necesitan en conexión con el desplazamiento de trabajadores. Como se ha indicado, la nueva regulación del desplazamiento obliga a garantizar una retribución igual que la aplicable en el lugar al que se desplaza el trabajador. La responsabilidad de reunir esa información recae en los Estados miembros, pero se pretende reducir la incertidumbre jurídica facilitando un acceso único a toda la información disponible. Esto puede contribuir a una significativa reducción de la carga administrativa para las empresas asociada a la nueva regulación y, por tanto, a impedir dificultades adicionales al desplazamiento.

En particular, la ALE tiene el encargo de mejorar la disponibilidad, calidad y accesibilidad de la información pertinente sobre los derechos y obligaciones relacionados con la movilidad laboral en un sitio web único para toda la UE en todos los idiomas.

La ALE tiene también como objetivo facilitar la cooperación entre los organismos nacionales para ofrecer a los empleadores orientación y asistencia sobre la movilidad laboral. Sin embargo, todavía es pronto para determinar qué alcance tendrá esa función en la práctica.
- Promover y organizar inspecciones laborales vinculadas al fraude en la movilidad laboral. La ALE podrá coordinar inspecciones nacionales conjuntas simultáneamente en varios países para casos relacionados con la movilidad laboral que traspasen las fronteras internas de la UE. Aunque tendrá que ir de la mano de las inspecciones nacionales, se le da un papel importante y activo, ya que podrá promover las inspecciones por su propia iniciativa y será la que preste el apoyo logístico y organizativo. Las inspecciones nacionales no estarán obligadas a participar, pero, en el caso de decidir no hacerlo, no tendrán derecho de veto si otras autoridades deciden seguir adelante y sí se les podrá pedir que justifiquen su negativa, lo que permitirá ejercer una presión que, previsiblemente, reducirá la falta de colaboración. Las inspecciones se seguirán realizando de acuerdo con las normas de cada país, pero podrán contar con la participación del personal de la agencia y esta prestará apoyo organizativo (incluidos los servicios de traducción e interpretación tan necesarios en la relación entre autoridades nacionales) e incluso asesoramiento jurídico.

- La ALE trabajará, también, en desarrollar un mejor intercambio de información entre autoridades de inspección, la base para una labor inspectora más eficaz en el futuro. Para ello fomentará el desarrollo y uso de herramientas de intercambio electrónico y de bases de datos para detección del fraude en tiempo real y desarrollará y aplicará marcos de interoperabilidad de información entre autoridades nacionales y con la propia ALE. 
Además, desarrollará sus propias capacidades de análisis sobre la movilidad laboral y la coordinación de sistemas de seguridad social, en particular en los ámbitos de fraude, explotación, discriminación o seguridad y salud en el trabajo. De hecho, la ALE ejercerá la presidencia de la Plataforma de Lucha contra el Trabajo no Declarado ${ }^{4}$, que viene funcionando desde 2016 para reforzar las capacidades de las autoridades nacionales ${ }^{5}$.

- Asimismo, la ALE tiene como función facilitar los procedimientos transfronterizos de ejecución de sanciones y multas derivadas del incumplimiento de la normativa europea sobre movilidad.

- Finalmente, como mecanismo complementario de su actuación, la ALE servirá de mediador entre autoridades nacionales en casos de discrepancia acerca de cómo resolver conflictos sobre la movilidad laboral, desbloqueando expedientes que actualmente tardan años en solucionarse.

En definitiva, las empresas pueden esperar que con el funcionamiento de esta autoridad aumente la efectividad del control del desplazamiento de trabajadores. No tardarán en verse inspecciones simultáneas en varios países de la UE persiguiendo prácticas fraudulentas o abusivas $^{6}$.

\footnotetext{
4 Creada por la Decisión (UE) 2016/344 del Parlamento Europeo y del Consejo de 9 de marzo de 2016 relativa a la creación de una Plataforma europea para reforzar la cooperación en materia de lucha contra el trabajo no declarado.

5 Puede obtenerse más información en la página de la Comisión Europea sobre la Plataforma: https://ec.europa.eu/social/main.jsp?cat/d= 1299\&/angld $=e s$

6 De hecho, en el primer día de funcionamiento de la ALE, la Confederación Europea de Sindicatos (ETUC por sus siglas en inglés) ya presentó una denuncia de prácticas abusivas en varios países centroeuropeos.
}

\section{Nueva norma sobre condiciones de trabajo}

Como parte del impulso para reforzar la respuesta europea a las consecuencias de la crisis, la Comisión presentó, como parte de un paquete de «justicia social» en marzo de 2018, una propuesta para actualizar y reforzar las normas sobre condiciones de contratación laboral.

El resultado ha sido la adopción de la directiva sobre condiciones de trabajo estables y predecibles publicada en julio de 2019 (Directiva (UE) 2019/1152). La directiva puede considerarse el germen de un marco europeo de relaciones laborales. Aunque es ciertamente incompleto, contiene los elementos básicos de un nivel mínimo europeo de protección en las condiciones laborales, con especial atención a las situaciones de mayor precariedad.

La directiva se construye sobre un antecedente de 1991(Directiva 91/533/CEE del Consejo), referido a la información a proporcionar a los trabajadores sobre su contratación laboral, pero lo desarrolla entrando en nuevos ámbitos sustanciales. La directiva establece un contenido de información más amplio y con plazos más cortos (de una semana para la mayor parte de la información a proporcionar), así como con elementos añadidos para el caso de trabajadores desplazados que concuerda con la revisión de la directiva de posting.

Entre la información que, como novedad, deberán proporcionar los empleadores está la de la duración y condiciones del periodo de prueba, el derecho a formación a cargo del empleador, el procedimiento de terminación del contrato, el método de pago de la remuneración y, especialmente, si el patrón de trabajo es predecible o no y, en este último caso, la cantidad de horas garantizadas, los días y horas de referencia o el periodo mínimo de preaviso. $\triangleright$ 
Pero el contenido con mayor interés, especialmente para las empresas que operan en el ámbito europeo, es el de las normas mínimas de protección que establece para todos los países de la UE:

- Una duración máxima de seis meses del periodo de prueba que puede establecerse en los contratos, salvo casos excepcionales?.

- La prohibición general de establecer cláusulas de exclusividad que impidan o penalicen a un trabajador por tener otra relación laboral (fuera de su horario de trabajo, claro está). No obstante, estas cláusulas podrán admitirse en cada país para prevenir conflictos de interés, por motivos de seguridad y salud en el trabajo (para evitar horarios excesivos, por ejemplo) o de confidencialidad. Se pretende con ello evitar una práctica que estaba extendiéndose en actividades nada sospechosas de generar conflictos de interés o confidencialidad y que limitaban injustificadamente la libertad de los trabajadores.

- Medidas limitadoras de los casos de mayor precariedad laboral. Así, se permite a los trabajadores con contratos sin horario fijo negarse a aceptar una demanda de su empleador si el régimen de jornada no tiene un esquema predecible o si no le llega un preaviso en tiempo razonable. Además, si es el empresario quien cancela sin preaviso razonable, el trabajador tendrá garantizado el derecho a indemnización. La directiva obliga a los Estados o bien a limitar estos contratos a demanda, o bien a sujetarlos a la presunción de

7 Los que determine cada Estado en función de la naturaleza del empleo o en protección del trabajador. Para los contratos temporales se ajustará en función de su duración. que garantizan un mínimo de horas (y la correspondiente retribución).

Se pretende con todo ello frenar los abusos que se venían cometiendo con estos contratos en países como Reino Unido o Países Bajos y que estaban llegando a convertirse en un modo de funcionamiento de ciertas empresas basado en la precariedad.

- Medidas generales de protección. La directiva también establece un marco general de protección de derechos laborales, que será el mínimo común para toda la UE y consiste en: la obligación de los Estados de garantizar el derecho del trabajador a reclamar y a recibir una atención oportuna y efectiva, la posibilidad de establecer presunciones favorables al trabajador, la garantía de acceso a un sistema de resolución de litigios eficaz e imparcial, la protección frente a un trato o consecuencias desfavorables por ejercer sus derechos o la protección frente al despido por el mismo motivo con inversión de la carga de la prueba para el empleador.

- Otro elemento interesante es la exigencia que establece la directiva de que corra por cuenta de la empresa el coste de la formación que sea obligatoria (según normativa o convenio) para ejercer las funciones que se piden al trabajador. Esta obligación no alcanza, sin embargo, a la necesaria para obtener o renovar las cualificaciones profesionales ${ }^{8}$.

Lo previsto en la directiva tendrá que estar traspuesto a la normativa nacional el 1 de agosto de 2022 a más tardar y se aplicará a $\triangleright$

8 Corresponde a la trasposición nacional trazar la frontera entre estos dos conceptos, que en algunos casos pueden resultar cercanos. 
todas las relaciones laborales existentes entonces, excepto en lo que se refiere a la información a proporcionar a los trabajadores, que se aplicará solo a solicitud del interesado.

En general, estas medidas no suponen cambios apreciables para España porque ya hay en la normativa nacional garantías equivalentes o superiores. Sin embargo, no parece aventurado pensar que estas disposiciones estén llamadas a evolucionar hacia un marco más completo y con un mínimo común más reforzado. Además, una vez establecidos los mínimos en la normativa europea, se activa la actuación del Tribunal de Justicia Europeo, que por su actividad de resolución de cuestiones prejudiciales tiene ya un papel muy activo en el ámbito sociolaboral.

\section{La directiva sobre conciliación laboral}

Con objetivos distintos, pero también efectos directos en el ámbito laboral de las empresas y no solo de aquellas que desplazan trabajadores, la UE acaba de adoptar una nueva directiva sobre medidas de conciliación de la vida laboral y personal: Directiva (UE) 2019/1158.

La directiva responde al objetivo de aumentar la participación de las mujeres en el empleo facilitando la conciliación de la vida laboral y personal y, en particular, contribuyendo a reequilibrar el reparto de las tareas de cuidados en el hogar. Este es un factor diferencial entre hombres y mujeres con gran peso en las decisiones laborales de estas últimas.

Las obligaciones derivadas de la nueva normativa comunitaria son para los Estados, pero también para las empresas, que deberán estar preparadas para atender solicitudes de organización flexible del trabajo en favor de la conciliación o, en su caso, justificar debidamente por qué no pueden atenderlas.

La directiva establece a partir de 2022:

- Un permiso de paternidad de diez días retribuidos al nivel de baja por enfermedad común, a disfrutar "con ocasión del nacimiento» del hijo, aunque permite a los países establecer modalidades de disfrute flexibles. Este permiso tiene una duración y nivel de retribución garantizada inferior al que se disfruta actualmente en España. Con la directiva se cierra, aunque sea solo ligeramente, la brecha con otros países ${ }^{9}$.

- Un permiso parental de cuatro meses, parcialmente retribuido por cada niño. A diferencia del permiso de paternidad, que es conocido y superado por la legislación española, el permiso parental, aunque existe, tiene muy poco uso en nuestro país. La razón es que hasta ahora no era remunerado.

La nueva regulación europea obligará a que al menos dos meses sean compensados económicamente, si bien deja a decisión nacional el nivel de esa compensación ${ }^{10}$. El permiso será disfrutable por los dos progenitores por cada niño menor a una determinada edad a fijar por cada país, pero en ningún caso superior a los ocho años. Los dos meses retribuidos del permiso serán intransferibles entre los padres.

Además, la directiva obliga a las normas nacionales a garantizar que ese permiso parental pueda disfrutarse con $\triangle$

9 Como República Checa, Eslovaquia, Croacia o Chipre, o, en menor medida, Italia, Austria o Grecia.

10 La obligación de compensar las últimas dos semanas de la parte remunerada entrará en vigor más tarde, en agosto de 2024. 
«fórmulas flexibles». Los empresarios deberán estudiar las solicitudes de disfrute flexible y motivar en un plazo razonable cualquier denegación.

Los trabajadores deberán avisar con antelación de su intención de disfrutar del permiso, en un plazo que se establecerá a nivel nacional. También podrá regularse a nivel nacional que el empleador pueda aplazar la concesión del permiso por un «periodo razonable», alegando por escrito que alteraría seriamente el buen funcionamiento de la empresa. En ese caso, la empresa debe ofrecer como alternativa formas flexibles de disfrute del permiso parental.

- Un permiso de cuidadores de cinco días por año y trabajador para atender las necesidades de cuidados de sus familiares. Los detalles de este permiso se dejan completamente a la decisión de los Estados, que podrán supeditarlo a que se justifique la necesidad del permiso (como sucede en España) o establecer condiciones de uso por días. Hay que tener en cuenta que este permiso se añade al permiso por causa de fuerza mayor, ya existente y que la directiva renueva. Este permiso permite ausentarse del trabajo por motivos familiares urgentes, enfermedad o accidente en las condiciones que determine cada país.

- El derecho a solicitar condiciones de trabajo flexibles y a obtener una respuesta fundamentada sobre esa solicitud. Igual que con la directiva de condiciones de trabajo, la de conciliación introduce con carácter general este derecho de los trabajadores, en este caso para todos los trabajadores con hijos hasta una edad a fijar a nivel nacional, pero siempre por encima de los ocho años. Este derecho podrá condicionarse a una antigüedad en la empresa, pero no superior a los seis meses. También podrá establecerse una duración, al final de la cual el trabajador tendrá derecho a volver a su modo de trabajo original. Asimismo, el trabajador podrá solicitar una vuelta antes de ese periodo, aunque esto podrá ser rechazado justificadamente.

De esta forma, se avanza de manera significativa en establecer la obligación de las empresas de ofrecer fórmulas de trabajo flexibles o bien de justificar adecuadamente la negativa. Será la jurisprudencia la que vaya delimitando los criterios y argumentos admisibles para esta negativa.

- Por último, la directiva introduce garantías de protección de los trabajadores que soliciten o que hagan uso de los permisos o de los modos de trabajo flexibles, con condiciones similares a las de la Directiva de Condiciones de Trabajo (medidas contra discriminación o trato desfavorable y protección contra el despido con inversión de la carga de la prueba). Adicionalmente, deberá estar garantizado el mantenimiento del puesto y las cotizaciones durante el disfrute de los permisos.

El impacto concreto de la directiva de conciliación sobre cada país puede ser muy diferente, dada la diversidad de partida de los sistemas nacionales de permisos por motivos familiares y el amplio margen de flexibilidad de la directiva para su trasposición. Además de los aspectos de cada permiso que se dejan al nivel nacional de decisión, la directiva permite, en una cláusula llamada «pasarela», tener en cuenta el conjunto de permisos (o «periodos de $D$ 
ausencia del trabajo») relacionados con la familia y cualquier remuneración para dar por cumplidas las obligaciones de la directiva.

En España, la reciente ampliación del permiso de paternidad, con un objetivo de dieciséis semanas plenamente retribuidas, acerca el total de los permisos disfrutables a lo previsto en la directiva, lo que en cierto modo hace gradual su impacto económico general y sobre las empresas.

En todo caso, la directiva de conciliación tiene un impacto evidente sobre el funcionamiento de las empresas con la introducción en la normativa comunitaria del derecho a solicitar condiciones flexibles de trabajo para todos los padres (de niños de hasta al menos ocho años). Esto obligará a las empresas a estar preparadas para atender estas solicitudes o al menos para justificar motivadamente por qué las rechazan. El permiso parental y la obligación de garantizar fórmulas flexibles para su disfrute pueden suponer igualmente un reto organizativo al que las empresas deberán hacer frente.

\section{Otros avances en materia laboral}

Las presentadas hasta ahora son las normas más relevantes aprobadas recientemente en la UE con incidencia en el ámbito laboral, pero no las únicas. Otras normas más horizontales o, por el contrario, con incidencia estrictamente sectorial están en proceso de incorporarse al marco regulatorio de la UE.

\subsection{Actualización de la normativa en materia de sustancias carcinógenas}

Durante 2017-2019 la UE ha continuado con el programa de actualización de su normativa en materia de protección de la salud de los trabajadores para ampliar su ámbito de aplicación e incluir o revisar los valores límite de exposición profesional a una serie de agentes químicos carcinógenos o mutágenos. Este programa se ha materializado en la aprobación de tres nuevas directivas: Directiva (UE) 2017/2398; Directiva (UE) 2019/130 y Directiva (UE) 2019/983; cuyo plazo de trasposición y aplicación irá alcanzándose de forma escalonada en los próximos años.

Por su naturaleza, es una normativa de efectos sectoriales, aunque en algunos casos muy notables. Entre los agentes que pueden destacarse de la última hornada de revisiones están los humos de combustión de los motores diésel, que afectan a actividades en las que esas emisiones se producen en entornos cerrados, como la minería, o los aceites usados en esos motores, pero también otros como las sales de sílice, el cadmio, el berilio o el formaldehído, de uso muy común en las actividades sanitarias.

\subsection{Otras novedades normativas}

También está a punto de publicarse una norma sobre la que recientemente se ha alcanzado un acuerdo definitivo en el, a veces, prolongado procedimiento de toma de decisiones de la UE. Se trata de una propuesta de directiva sobre los procedimientos de reestructuración empresarial que tengan una dimensión comunitaria ${ }^{11}$, por ejemplo, por afectar a centros de trabajo en más de un país de la UE. Estos procesos en el futuro tendrán que pasar por un procedimiento reglado destinado a $\triangleright$

11 Propuesta de Directiva del Parlamento Europeo y del Consejo por la que se modifica la Directiva (UE) $2017 / 1132$ en lo que atañe a las transformaciones, fusiones y escisiones transfronterizas. 
proteger los derechos de los trabajadores (además de a los acreedores o pequeños accionistas).

La propuesta establece la obligación de contar con un informe sobre los efectos en los trabajadores y sus derechos, así como la de respetar un periodo de consultas. Asimismo, establece que las normas de representación de los trabajadores serán las del país de origen de la empresa siempre que las del país del destino no aseguren un nivel igual en cuanto los derechos de participación, información y consulta.

\section{Mirando hacia adelante}

Las iniciativas recientemente aprobadas suponen un avance sustancial hacia un marco europeo de regulación de aspectos esenciales de las cuestiones laborales. Pero ¿es la culminación de un proceso o cabe esperar que se siga avanzando? Probablemente no serán las últimas piezas en la creciente importancia del nivel comunitario en la regulación laboral.

El 1 de diciembre está previsto que se inicie una nueva etapa en la Comisión Europea. Con las señales emitidas hasta ahora, cabe esperar que la Comisión, como encargada de las iniciativas legislativas, continúe lanzando iniciativas a nivel comunitario en materia laboral. De las mencionadas en su propuesta de futuras actuaciones por la que será la nueva presidenta de la Comisión Europea, Ursula Von der Leyen ${ }^{12}$, cabe destacar las siguientes:

- Contar con un «instrumento jurídico» que garantice que todos los trabajadores de

12 Documento A Union that strives for more. My agenda for Europe. Political Guidelines For The Next European Commission 2019-2024. la UE tienen un salario mínimo. Esto responde a demandas de algunos países (particularmente Alemania, que lo ha identificado como una de las prioridades de su presidencia en el segundo semestre de 2020), de las organizaciones sindicales y de algunos grupos políticos. Sin embargo, el margen de actuación a nivel comunitario es estrecho, porque los tratados niegan expresamente a las instituciones de la UE la competencia sobre salarios ${ }^{13}$. Por ello, es previsible que la propuesta se refiera a elementos de garantía y procedimiento sobre la existencia de esos salarios mínimos, su alcance y su carácter no discriminatorio o sobre cómo deben actualizarse regularmente.

- Examinar vías para mejorar las condiciones de los trabajadores de plataformas. Aunque no se han dado detalles de las propuestas posibles en esta materia, lo cierto es que hay una preocupación bastante extendida por las condiciones de los llamados «colaboradores» de las plataformas, en particular de los repartidores. Muy probablemente, en este campo se verá avanzar a la UE planteando nuevos elementos de regulación laboral sustantiva.

\section{Conclusiones}

Los últimos meses han evidenciado una tendencia a incrementar el ámbito y alcance de la normativa comunitaria en materia laboral. Son pasos hacia la configuración de un marco normativo a escala europea que busca de $\triangleright$

13 Artículo 153.5 del Tratado de Funcionamiento de la Unión Europea. 
manera explícita afianzar la dimensión social de la Unión Europea. En buena medida se derivan del Pilar Europeo de Derechos Sociales, adoptado en noviembre de 2017, por las tres instituciones comunitarias mediante una declaración solemne ${ }^{14}$.

El pilar y las iniciativas asociadas a él forman parte de un intento de recuperar la confianza de los ciudadanos europeos en el proyecto económico, político y social que alimenta la integración europea. En el ámbito de la movilidad laboral la necesidad de recuperar la confianza es especialmente marcada dadas las desconfianzas y divisiones que, en distintos ámbitos, ha venido generando la mayor presencia de trabajadores de otros países comunitarios. Es un terreno lleno de tensiones donde seguramente todavía no se ha alcanzado el deseable equilibrio.

Por ello, aunque algunos países muestren actualmente signos de fatiga y pidan «consolidar» la situación actual y no seguir avanzando, es previsible que sigan progresando nuevas iniciativas de refuerzo de esa dimensión social que ofrezcan garantías a los trabajadores a la vez que se profundiza en la integración económica con más movilidad laboral. El papel de la nueva Autoridad Laboral Europea será crucial en la consolidación de esa tendencia de manera equilibrada.

Todo ello no puede pasar desapercibido para las empresas porque afecta a aspectos importantes de su actividad. Así, aquellas que quieren hacer uso de la libertad de prestación de servicios, y para ello desplazan trabajadores a otro país de la UE, deben ser particularmente conscientes de los cambios que introduce la

\footnotetext{
14 La declaración puede encontrarse en http://data.consilium.europa. eu/doc/document/st-13129-2017-init/es/pdf

Más información sobre el pilar en https://ec.europa.eu/commission/ priorities/deeper-and-fairer-economic-and-monetary-union/europeanpillar-social-rights/european-pillar-social-rights-20-principles_es
}

nueva normativa (y de la posibilidad de que todavía lleguen más).

Por su parte, las empresas de todos los tamaños, incluso si no tienen actividad más allá de las fronteras, verán, por ejemplo, cómo progresan los mecanismos de flexibilidad interna impulsados desde la UE, lo que puede ser un motor de cambios organizativos que mejoren su adaptabilidad y competitividad.

En definitiva, la tendencia que se percibe es que continuarán los avances en materia laboral a nivel comunitario. Las iniciativas que vayan completando ese marco comunitario de regulación laboral previsiblemente tendrán un impacto relevante en la actuación de las empresas.

\section{Bibliografía}

Comisión Europea (2019). Informe sobre la aplicación y ejecución de la Directiva 2014/67/UE del Parlamento Europeo y del Consejo, de 15 de mayo de 2014, relativa a la garantía de cumplimiento de la Directiva 96/71/CE sobre el desplazamiento de trabajadores efectuado en el marco de una prestación de servicios, y por la que se modifica el Reglamento (UE) n. ${ }^{\circ} 1024 / 2012$, relativo a la cooperación administrativa a través del Sistema de Información del Mercado Interior (Reglamento IMI).

De Wispelaere, F., y Pacolet, J. (2017). Posting of workers. Report on A1 portable documents issued in 2016.

Directiva 96/71/CE del Parlamento Europeo y del Consejo, de 16 de diciembre de 1996, sobre el desplazamiento de trabajadores efectuado en el marco de una prestación de servicios.

Directiva 2014/67/UE del Parlamento Europeo y del Consejo, de 15 de mayo de 2014, relativa a la garantía de cumplimiento de la Directiva 96/71/CE, sobre el desplazamiento de trabajadores efectuado en el marco de una prestación de servicios, y por la que se modifica el Reglamento $D$ 
(UE) n.․ 1024/2012, relativo a la cooperación administrativa a través del Sistema de Información del Mercado Interior (Reglamento IMI).

Directiva (UE) 2017/2398 del Parlamento Europeo y del Consejo, de 12 de diciembre de 2017, por la que se modifica la Directiva 2004/37/CE relativa a la protección de los trabajadores contra los riesgos relacionados con la exposición a agentes carcinógenos o mutágenos durante el trabajo.

Directiva (UE) 2018/957 del Parlamento Europeo y del Consejo, de 28 de junio de 2018, que modifica la Directiva 96/71/CE sobre el desplazamiento de trabajadores efectuado en el marco de una prestación de servicios.

Directiva (UE) 2019/130 del Parlamento Europeo y del Consejo, de 16 de enero de 2019, por la que se modifica la Directiva 2004/37/CE relativa a la protección de los trabajadores contra los riesgos relacionados con la exposición a agentes carcinógenos o mutágenos durante el trabajo.

Directiva (UE) 2019/983 del Parlamento Europeo y del Consejo, de 5 de junio de 2019, por la que se modifica la Directiva 2004/37/CE, relativa a la protección de los trabajadores contra los riesgos relacionados con la exposición a agentes carcinógenos o mutágenos durante el trabajo.
Directiva (UE) 2019/1158 del Parlamento Europeo y del Consejo, de 20 de junio de 2019, relativa a la conciliación de la vida familiar y la vida profesional de los progenitores y los cuidadores, y por la que se deroga la Directiva 2010/18/UE del Consejo.

Propuesta de Directiva del Parlamento Europeo y del Consejo por la que se modifica la Directiva (UE) 2017/1132 en lo que atañe a las transformaciones, fusiones y escisiones transfronterizas.

Propuesta de Reglamento de Parlamento Europeo y del Consejo por el que se modifican el Reglamento (CE) n.ㅇ 883/2004 sobre la coordinación de los sistemas de seguridad social, y el Reglamento (CE) n. 987/2009 por el que se adoptan las normas de aplicación del Reglamento (CE) n. ${ }^{\circ} 883 / 2004$.

Reglamento (UE) 2019/1149 del Parlamento Europeo y del Consejo, de 20 de junio de 2019, por el que se crea la Autoridad Laboral Europea, se modifican los Reglamentos (CE) n. ${ }^{\circ} 883 / 2004$, (UE) n.․ 492/2011 y (UE) 2016/589 y se deroga la Decisión (UE) 2016/344.

Von der Leyen, U. (2019). A Union that strives for more. My agenda for Europe. Political Guidelines For The Next European Commission 2019-2024. 